Article

\title{
Hierarchical H-MOR Zeolite Supported Vanadium Oxide for Dimethyl Ether Direct Oxidation
}

\author{
Wenfeng Wang ${ }^{1,2}$, Xiujuan Gao ${ }^{1,2}$, Ru Feng ${ }^{1,2}$, Qi Yang ${ }^{1,2}$, Tao Zhang ${ }^{1}$, Junfeng Zhang ${ }^{1}{ }^{1}$, \\ Qingde Zhang ${ }^{1, *}$, Yizhuo Han ${ }^{1}$ and Yisheng Tan ${ }^{1, *}$ \\ 1 State Key Laboratory of Coal Conversion, Institute of Coal Chemistry, Chinese Academy of Sciences, \\ Taiyuan 030001, China \\ 2 University of Chinese Academy of Sciences, Beijing 100049, China \\ * Correspondence: qdzhang@sxicc.ac.cn (Q.Z.); tan@sxicc.ac.cn (Y.T.); \\ Tel.: +86-351-4044-388 (Q.Z.); +86-351-4044-287 (Y.T.)
}

Received: 27 June 2019; Accepted: 15 July 2019; Published: 23 July 2019

\begin{abstract}
A series of hierarchical H-MOR zeolites with different pore structure were designed and synthesized by alkaline and alkaline-acid post-synthesis methods. The catalytic performance of hierarchical H-MOR zeolite-supported vanadium oxide was investigated for dimethyl ether (DME) direct oxidation. Different pore structures apparently affect the distribution of oxidation product distribution, especially the selectivity of DMMx and CO. The formation of mesopores for $10 \% \mathrm{~V}_{2} \mathrm{O}_{5} /$ deAlmm-H-MOR markedly improved the DMMx selectivity up to $78.2 \%$ from $60.0 \%$, and more notably, $\mathrm{CO}$ selectivity dropped to zero compared to that of $10 \% \mathrm{~V}_{2} \mathrm{O}_{5} / \mathrm{H}-\mathrm{MOR}$. The hierarchical H-MOR zeolites were confirmed to be successfully prepared by the post-synthesis method. Due to the presence of mesoporous structure, the dispersion of vanadium oxide species was enhanced, which could improve the reducibility of vanadium oxide species and also make better contact with the acid sites of zeolite to exert the synergistic effect of the bifunctional active sites. More importantly, the creation of mesopores was proved to be favorable to the mass transfer of intermediate and products to avoid the occurrence of secondary reaction, which could effectively suppress the formation of by-products. This work is helpful for us to provide a novel insight to design the catalyst with suitable pore structure to effectively synthesize diesel fuel additives from DME direct oxidation.
\end{abstract}

Keywords: dimethyl ether; polyoxymethylene dimethyl ethers; hierarchical zeolite; vanadium oxide; direct oxidation

\section{Introduction}

Dimethyl ether (DME) is a clean fuel and a potential non-petroleum route chemical material. Moreover, it can be widely synthesized by one-step method from syngas generated from coal, renewable biomass, and natural gas [1,2]. DME has a high cetane number of 55-60, which makes it an ideal fuel, but the low boiling point of DME limits its direct blending with diesel [3]. Polyoxymethylene dimethyl ethers (DMMx) have the traits of lower vapor pressure, higher viscosity and cetane number. It is considered to be promising diesel fuel additives to improve the engine combustion performance and reduce particulate matter emissions, which could significantly decrease environment pollution $[4,5]$. At present, the condensation of methanol and its downstream products (including formaldehyde and trioxymethylene, etc.) over acid catalysts is the main route for DMMx synthesis, and the selective oxidation of methanol or dimethyl ether has been investigated to synthesize DMM [6,7].

In comparison, oxidizing DME directly to synthesize DMMx is considered as a very competitive and environmentally friendly route for the synthesis of clean fuel additives due to the advantages of short process, low investment, low $\mathrm{CO}_{2}$ emissions, and high energy efficiency. However, the activation 
of the DME molecule is very difficult at lower temperature because of its high stability, while higher temperature easily leads to deep oxidation of DME along with the formation of by-products and makes product complex [8-10]. Especially, the synthesis of the larger DMMx molecules with longer C-O chain from small DME molecule is very complicated and difficult. Moreover, the formed products might be subjected to steric constraint over acid catalysts to undergo the secondary reaction, which easily leads to the formation of by-products and the decrease of target product selectivity (the molecular formula and structure of the mentioned reactant and products are shown in Table 1) [11]. Thus, the activation and the highly efficient conversion of DME are very challenging. The appropriate redox and acid sites have been proved to be crucial factors and investigated systemically for the synthesis of DMMx [7-10,12-15], but to date, the effect of transport constraints due to the pore structure of support on product distribution has not been investigated. Given that the H-MOR has two pore systems consisted of 12-MR channels with the dimensions of $0.65 \times 0.70 \mathrm{~nm}$ connected via 8-MR side pocket of $0.26 \times 0.57 \mathrm{~nm}$ as shown in Scheme 1, it is expected to be a promising model for us to investigate the catalytic performance of DME direct oxidation as a function of pore structure. Since the 8-MR channels exist in H-MOR zeolite, it may hinder the diffusion of reactant and products, resulting in the proceeding of the secondary reaction to form more by-products. Hence, fabricating the mesopores structure in the zeolite crystals is an efficient method to solve the mass transfer limitation of zeolite micropores to improve the catalytic performance [16,17]. Many effective approaches have been developed, and one of them for the formation of the mesopores in the zeolite crystals is through post-synthesis treatment of conventional zeolites [18-21]. Pastvova et al. have reported that the controlled alkaline-based treatments of the MOR framework lead to the better preservation of acid sites and the formation of well-developed secondary mesoporosity. The existence of mesopores structure results in high yields of branched isomers and limits nonselective subsequent cracking reactions [22]. Zhang et al. found that the formation of mesopores for hierarchical porous MOR used as the supports could be beneficial to the dispersion of $\mathrm{Pt}$ species which can improve the contact of the reactants to the active sites. Meanwhile, hierarchical porous MOR with mesopores structure could accelerate the mass transfer to exhibit superior catalytic performance for toluene combustion [23].



Scheme 1. Topology of H-MOR zeolite consisting of 12-ring channel and 8-ring side pockets. 
Table 1. The list of the molecular formula and structure of the mentioned reactant and products.

\begin{tabular}{|c|c|c|c|c|c|}
\hline Substances & Molecular Formula & Molecular Structure & Substances & $\begin{array}{l}\text { Molecular } \\
\text { Formula }\end{array}$ & $\begin{array}{l}\text { Molecular } \\
\text { Structure }\end{array}$ \\
\hline DME & $\mathrm{CH}_{3} \mathrm{OCH}_{3}$ & & $\mathrm{CH}_{3} \mathrm{OH}$ & $\mathrm{CH}_{3} \mathrm{OH}$ & \\
\hline DMM & $\mathrm{CH}_{3} \mathrm{OCH}_{2} \mathrm{OCH}_{3}$ & & MF & $\mathrm{HCOOCH}_{3}$ & \\
\hline $\mathrm{DMM}_{2}$ & $\mathrm{CH}_{3} \mathrm{O}\left(\mathrm{CH}_{2} \mathrm{O}\right)_{2} \mathrm{CH}_{3}$ & & $\mathrm{CO}$ & $\mathrm{CO}$ & \\
\hline $\mathrm{DMM}_{3}$ & $\mathrm{CH}_{3} \mathrm{O}\left(\mathrm{CH}_{2} \mathrm{O}\right)_{3} \mathrm{CH}_{3}$ & & $\mathrm{CO}_{2}$ & $\mathrm{CO}_{2}$ & \\
\hline $\mathrm{HCHO}$ & $\mathrm{HCHO}$ & c & $\mathrm{CH}_{4}$ & $\mathrm{CH}_{4}$ & \\
\hline
\end{tabular}

In this work, the hierarchical H-MOR zeolites with different pores structures are designed and successfully synthesized by controlling the treatment procedure of desilication with alkaline solution and dealumination with oxalic acid. Then, the prepared H-MOR is used to support vanadium oxide species to build bifunctional catalysts in consideration of the superior redox ability widely used in heterogeneous oxidation [24-27]. The obtained catalysts were investigated for DME direct oxidation. The experimental results show that $10 \% \mathrm{~V}_{2} \mathrm{O}_{5} / \mathrm{deAlmm}-\mathrm{H}-\mathrm{MOR}$ catalyst with the presence of mesopores could effectively change the oxidation products distribution. The DMMx selectivity improves up to $78.2 \%$ from $60.0 \%$, and more obviously, the CO selectivity drops to zero. The fabrication of mesopores could accelerate the mass transport to avoid the secondary reaction of formed products, which is beneficial to the promotion of catalytic performance of catalysts. A series of characterizations were performed in detail to expound the structure and chemical property of zeolites catalysts. Up to now, there is no report about the role of pore structure in the formation of DMMx from DME direct oxidation on zeolites supported metal oxide catalyst. The work could provide an indication for the designing of catalysts to realize the optimized synthesis of the lager DMMx molecules with longer $\mathrm{C}-\mathrm{O}$ chain.

\section{Results and Discussion}

\subsection{XRD Characterization}

Figure 1 shows the XRD patterns of unsupported zeolites and post-synthesis H-MOR zeolite-supported vanadium oxide catalysts. The intensity of the characteristic diffraction peaks for the supported H-MOR zeolite slightly changes, indicating that neither alkaline treatment nor subsequent acid-leached treatment decreases the crystallinity of supported catalysts, and it suggests a well-preserved MOR structure after the treatments (seen in Table 2 and Figure S1). In addition, there is no apparent diffraction peak assigning to crystalline $\mathrm{V}_{2} \mathrm{O}_{5}$ to be observed, which indicates the high dispersion of vanadium oxide species on the surface [28].

Table 2. Textural properties of $10 \% \mathrm{~V}_{2} \mathrm{O}_{5}$ supported on $\mathrm{H}-\mathrm{MOR}$ prepared by post-synthesis treatment.

\begin{tabular}{|c|c|c|c|c|c|c|c|}
\hline Catalysts & Cryst./\% ${ }^{a}$ & $\mathrm{Si} / \mathrm{Al}^{\mathrm{b}}$ & $\mathrm{Si} / \mathrm{Al}^{\mathrm{c}}$ & $\begin{array}{c}S_{B E T} d \\
\left(m^{2} g^{-1}\right)\end{array}$ & $\begin{array}{c}V_{\text {total }} \mathrm{e} \\
\left(\mathrm{cm}^{3} \mathrm{~g}^{-1}\right)\end{array}$ & $\begin{array}{c}V_{\text {micro }} f \\
\left(\mathrm{~cm}^{3} \mathrm{~g}^{-1}\right)\end{array}$ & $\begin{array}{c}V_{\text {meso }} \mathrm{g} \\
\left(\mathrm{cm}^{3} \mathrm{~g}^{-1}\right)\end{array}$ \\
\hline H-MOR & 100 & 9.6 & 8.0 & 542 & 0.276 & 0.189 & 0.087 \\
\hline mm-H-MOR & 95 & 7.4 & 7.2 & 564 & 0.343 & 0.176 & 0.167 \\
\hline deAlmm-H-MOR & 95 & 18.8 & 24.5 & 588 & 0.378 & 0.176 & 0.202 \\
\hline $10 \% \mathrm{~V}_{2} \mathrm{O}_{5} / \mathrm{H}-\mathrm{MOR}$ & 100 & 9.6 & 8.0 & 318 & 0.198 & 0.147 & 0.051 \\
\hline $10 \% \mathrm{~V}_{2} \mathrm{O}_{5} / \mathrm{mm}-\mathrm{H}-\mathrm{MOR}$ & 95 & 7.4 & 7.2 & 335 & 0.247 & 0.137 & 0.110 \\
\hline $10 \% \mathrm{~V}_{2} \mathrm{O}_{5} / \mathrm{deAlmm}-\mathrm{H}-\mathrm{MOR}$ & 94 & 18.8 & 24.5 & 318 & 0.251 & 0.128 & 0.123 \\
\hline
\end{tabular}

pore volume. ${ }^{\mathrm{f}}$ Micropore volume estimated from t-plot method. ${ }^{\mathrm{g}} \mathrm{V}_{\text {meso }}=\mathrm{V}_{\text {total }}-\mathrm{V}_{\text {micro }}$. 


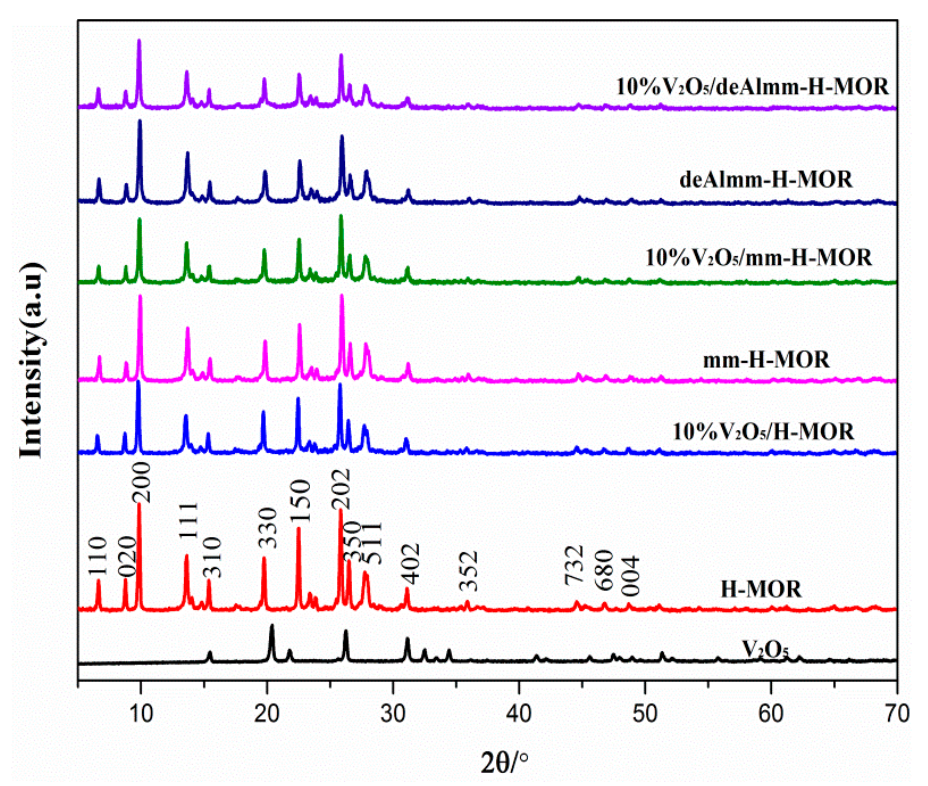

Figure 1. XRD spectra of unsupported zeolites and post-synthesis H-MOR zeolites-supported vanadium oxide catalysts.

\section{2. $\mathrm{N}_{2}$ Adsorption-Desorption Measurement}

The $\mathrm{N}_{2}$ adsorption-desorption characterization was performed to evaluate the textural structure of the unsupported zeolites and post-treatment H-MOR zeolites-supported vanadium oxide catalysts and the results are shown in Figure 2. The increased mesopores volume and the enhanced hysteresis loops for parent zeolites attest that the mesopores structure has been successfully prepared after post-treatment. Upon the introduction of vanadium oxide, the BET surface area and pore volume both decrease due to the blocking of vanadium oxide species with $10 \% \mathrm{wt}$. For the supported catalyst, $10 \% \mathrm{~V}_{2} \mathrm{O}_{5} / \mathrm{H}-\mathrm{MOR}$ catalyst presents a typical type I adsorption isotherm. While for $10 \% \mathrm{~V}_{2} \mathrm{O}_{5} / \mathrm{mm}-\mathrm{H}-\mathrm{MOR}$ and $10 \% \mathrm{~V}_{2} \mathrm{O}_{5} / \mathrm{deAlmm}-\mathrm{H}-\mathrm{MOR}$ catalysts, they both show typical characteristics of type I and type IV isotherm, and it could be seen that the hysteresis loops at $\mathrm{p} / \mathrm{p}_{0}=0.5-1.0$ over the post-synthesis H-MOR catalysts are enlarged due to the presence of mesopores. The structural parameters calculated from $\mathrm{N}_{2}$ adsorption-desorption isotherm are listed in Table 2. As is shown in Table 2, the mesopores volume of the $10 \% \mathrm{~V}_{2} \mathrm{O}_{5} / \mathrm{mm}-\mathrm{H}$-MOR catalyst by alkali-treatment increases to $0.110 \mathrm{~cm}^{3} \cdot \mathrm{g}^{-1}$, which is higher than that of $10 \% \mathrm{~V}_{2} \mathrm{O}_{5} / \mathrm{H}-\mathrm{MOR}$. The BET surface area also increases due to the formation of mesopores by desilication. Upon alkali-treatment and subsequent acid leaching treatment, an obvious increase in the mesopores volume for $10 \% \mathrm{~V}_{2} \mathrm{O}_{5} / \mathrm{deAlmm}-\mathrm{H}-\mathrm{MOR}$ is observed, and it evidences that alkali-treatment and subsequent acid leaching method is more favorable for the generation of mesopores structure. Furthermore, it can be clearly seen from the pore size distribution that there is a main peak centered at about $3.8 \mathrm{~nm}$ for all catalysts, and obviously, the intensity of the peak is further increased after post-treatments. Moreover, the peak at $12.5 \mathrm{~nm}$ is observed for the $10 \% \mathrm{~V}_{2} \mathrm{O}_{5} / \mathrm{mm}-\mathrm{H}-\mathrm{MOR}$ and $10 \% \mathrm{~V}_{2} \mathrm{O}_{5} / \mathrm{deAlmm}-\mathrm{H}-\mathrm{MOR}$. In summary, the hierarchical H-MOR zeolites with micro- and mesopores have been successfully synthesized through the post-treatments. The fabricated mesopores are considered to be beneficial to the accessibility of active species to reactant and also improve the diffusion of the reactants and products in the micro-mesoporous structure, which can effectively avoid the secondary reaction of intermediate and products to accordingly suppress the formation of the by-products $[23,29,30]$. 

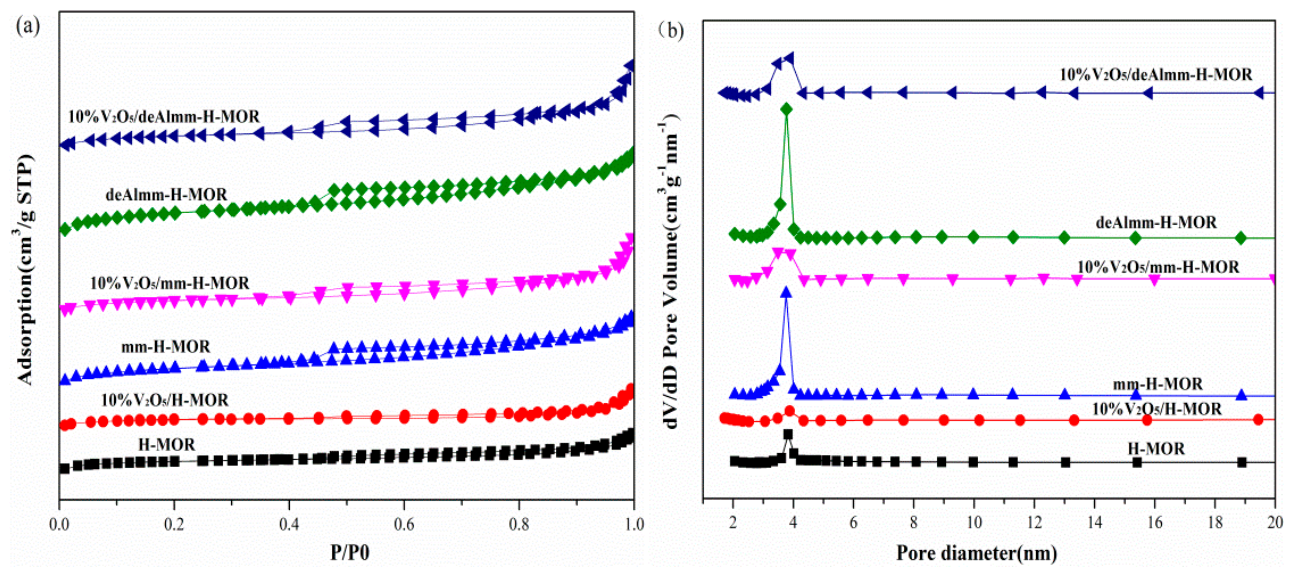

Figure 2. $\mathrm{N}_{2}$-adsorption isotherms (a) and pore size distribution (b) of unsupported zeolites and post-synthesis H-MOR zeolites-supported vanadium oxide catalysts.

\subsection{TEM}

Figure 3 shows the HR-TEM images of $10 \% \mathrm{~V}_{2} \mathrm{O}_{5} / \mathrm{H}-\mathrm{MOR}$ and the post-treatment H-MOR zeolites-supported vanadium oxide catalysts. For $10 \% \mathrm{~V}_{2} \mathrm{O}_{5} / \mathrm{H}-\mathrm{MOR}$ as reference, TEM images exhibit direct evidence that the intra-crystal mesopores structure are created over $10 \% \mathrm{~V}_{2} \mathrm{O}_{5} / \mathrm{mm}-\mathrm{H}-\mathrm{MOR}$ and $10 \% \mathrm{~V}_{2} \mathrm{O}_{5} /$ deAlmm-H-MOR catalysts, besides, it can be clearly seen that the pore size of fabricated mesopores is about $10 \mathrm{~nm}$. Moreover, no lattice fringes of crystalline $\mathrm{V}_{2} \mathrm{O}_{5}$ are observed, which indicates the high dispersion of the supported vanadium oxide species on the surface. The result is in good agreement with the conclusion from XRD characterization.
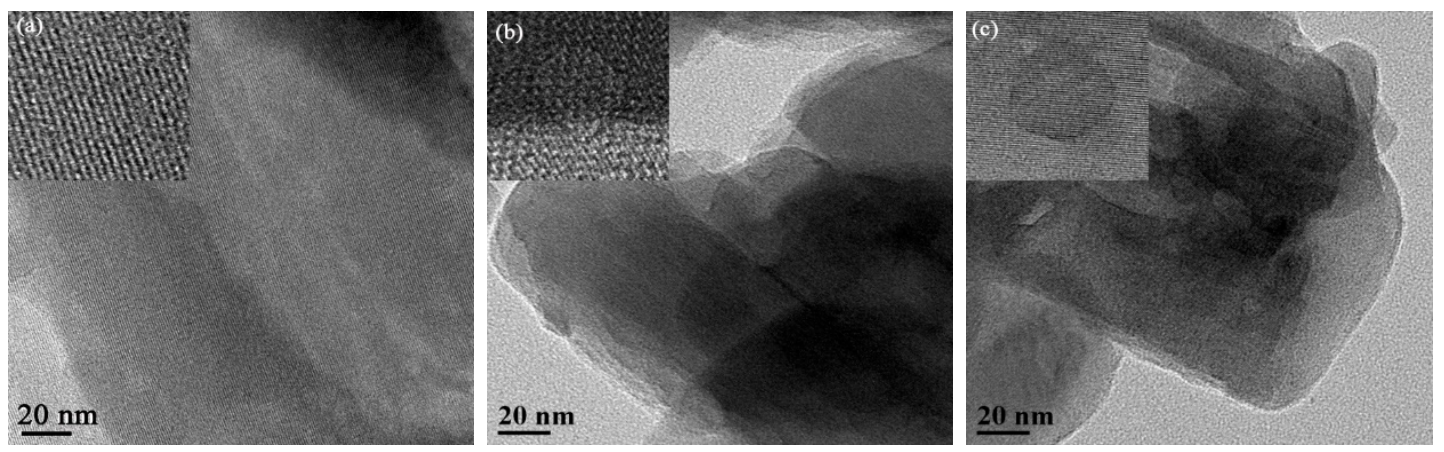

Figure 3. HR-TEM images of post-synthesis H-MOR zeolites-supported vanadium oxide catalysts (a) $10 \% \mathrm{~V}_{2} \mathrm{O}_{5} / \mathrm{H}-\mathrm{MOR}$, (b) $10 \% \mathrm{~V}_{2} \mathrm{O}_{5} / \mathrm{mm}-\mathrm{H}-\mathrm{MOR}$, and (c) $10 \% \mathrm{~V}_{2} \mathrm{O}_{5} /$ deAlmm-H-MOR.

\section{4. ${ }^{29}$ Si MAS NMR and ${ }^{27}$ Al MAS NMR}

${ }^{29} \mathrm{Si}$ and ${ }^{27} \mathrm{Al}$ MAS NMR were measured to investigate the variation of the $\mathrm{Si}$ and $\mathrm{Al}$ coordination upon the alkaline and alkaline-acid treatment. As shown in Figure 4A, the ${ }^{29} \mathrm{Si}$ MAS NMR spectrum of $10 \% \mathrm{~V}_{2} \mathrm{O}_{5} / \mathrm{H}-\mathrm{MOR}$ catalyst shows a broad peak, which can be deconvoluted to four peaks centered at $-115.9,-113.4,-108.2$, and $-105.6 \mathrm{ppm}$. The chemical shifts at -115.9 and $-113.4 \mathrm{ppm}$ are attributed to $\mathrm{Si}(4 \mathrm{Si}, 0 \mathrm{Al})$, and the latter two peaks are assigned to $\mathrm{Si}(3 \mathrm{Si}, 1 \mathrm{Al})$ [31]. Upon desilication with alkaline solution, the decrease of the proportion of the $\mathrm{Si}(4 \mathrm{Si}, 0 \mathrm{Al})$ unit is observed in comparison with $10 \% \mathrm{~V}_{2} \mathrm{O}_{5} / \mathrm{H}-\mathrm{MOR}$ (Table 3 ), suggesting that the silicon atom preferably extracts from $\mathrm{Si}(4 \mathrm{Si}, 0 \mathrm{Al}$ ), while the increase in the relative area of $\mathrm{Si}(3 \mathrm{Si}, 1 \mathrm{Al})$ peak might have resulted from the reintegration of the part of Al. The further acid washing of mm-H-MOR can significantly remove the extra-framework $\mathrm{Al}$ species [22], meanwhile, the increment of $\mathrm{Si} / \mathrm{Al}$ ratio calculated from chemical analysis and ${ }^{29} \mathrm{Si}$ MAS NMR indicates that the framework $\mathrm{Al}$ is also extracted in acid treatment. 
Figure $4 \mathrm{~B}$ shows the ${ }^{27} \mathrm{Al}$ MAS NMR spectra of the post-synthesis H-MOR zeolite-supported vanadium oxide catalysts. The spectrum of ${ }^{27} \mathrm{Al}$ MAS NMR for $10 \% \mathrm{~V}_{2} \mathrm{O}_{5} / \mathrm{H}-\mathrm{MOR}$ presents a main peak at about $55 \mathrm{ppm}$, which is ascribed to tetrahedral $\mathrm{Al}$ in zeolite framework, while the small band at 0 ppm is corresponding to extra-framework Al species [31], indicating that the Al species is predominant by the framework $\mathrm{Al}$ species, but it also has an amount of extra-framework $\mathrm{Al}$ species existing in the catalyst of $10 \% \mathrm{~V}_{2} \mathrm{O}_{5} / \mathrm{H}-\mathrm{MOR}$ (Table S2). In consistent with the result of ${ }^{29} \mathrm{Si}$ MAS NMR, the integration of $\mathrm{Al}$ leads to a slight increase of framework $\mathrm{Al}$ species, but it still consists of a number of EFAl species. After acid leaching treatment, it is found that an obvious reduction of extra-framework $\mathrm{Al}$ is observed in $10 \% \mathrm{~V}_{2} \mathrm{O}_{5} / \mathrm{deAlmm}-\mathrm{H}-\mathrm{MOR}$ due to the removal of EFAl species, which could result in the fabrication of larger mesopores volume and wider pore size.
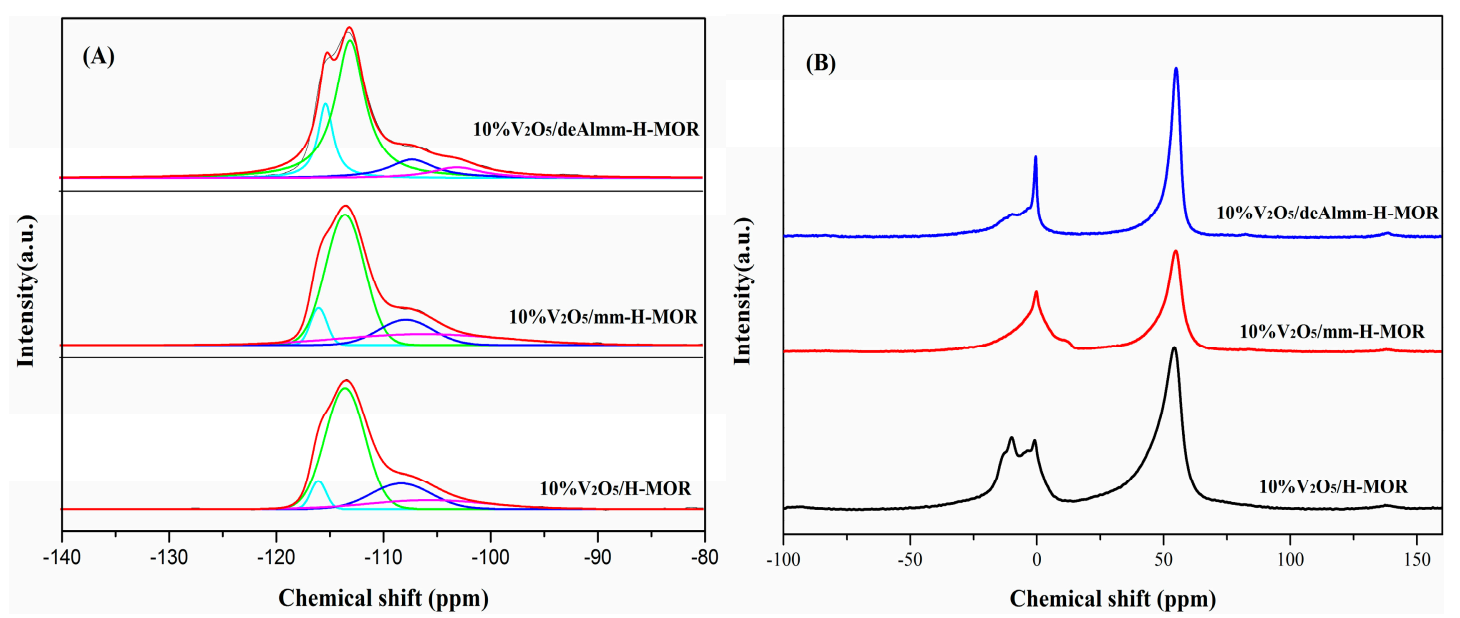

Figure 4. ${ }^{29} \mathrm{Si}$ MAS NMR (A) and ${ }^{27} \mathrm{Al}$ MAS NMR (B) spectra of post-synthesis H-MOR zeolites-supported vanadium oxide catalysts.

Table 3. Relative peak areas determined from ${ }^{29}$ Si MAS NMR.

\begin{tabular}{ccccccccc}
\hline Catalysts & $\begin{array}{c}\text { CS } \\
(\mathbf{p p m})\end{array}$ & $\mathbf{I}(\mathbf{\%})$ & $\begin{array}{c}\text { CS } \\
(\mathbf{p p m})\end{array}$ & $\mathbf{I}(\mathbf{\%})$ & $\begin{array}{c}\text { CS } \\
(\mathbf{p p m})\end{array}$ & $\mathbf{I}$ (\%) & $\begin{array}{c}\text { CS } \\
(\mathbf{p p m})\end{array}$ & $\mathbf{I}$ (\%) \\
\hline $10 \% \mathrm{~V}_{2} \mathrm{O}_{5} / \mathrm{H}-\mathrm{MOR}$ & -115.9 & 5.5 & -113.4 & 61.3 & -108.2 & 19.6 & -105.6 & 13.7 \\
$10 \% \mathrm{~V}_{2} \mathrm{O}_{5} / \mathrm{mm}-\mathrm{H}-\mathrm{MOR}$ & -115.8 & 6.9 & -113.4 & 57.3 & -107.7 & 15.4 & -106.0 & 20.4 \\
$10 \% \mathrm{~V}_{2} \mathrm{O}_{5} / \mathrm{deAlmm}-\mathrm{H}-\mathrm{MOR}$ & -115.2 & 17.3 & -112.9 & 61.7 & -107.1 & 12.9 & -102.9 & 8.1 \\
\hline
\end{tabular}

\subsection{X-ray Photoelectron Spectra (XPS)}

To understand the surface compositions and surface state of V species, the XPS technique was used with the results shown in Figure 5. The peaks with binding energies (BEs) at $518.0 \mathrm{eV}$ and 516.8 $\mathrm{eV}$ deconvoluted of $\mathrm{V} 2 \mathrm{p}_{3 / 2}$ line are ascribed to $\mathrm{V}^{5+}$ and $\mathrm{V}^{4+}$ species, respectively [32]. The oxidation state and the relative content of vanadium species analyzed by V2 $\mathrm{p}_{3 / 2}$ peak-fitting from XPS spectra are listed in Table 4. For all catalysts, $\mathrm{V}^{5+}$ and $\mathrm{V}^{4+}$ species both present on the catalysts and the $\mathrm{V}^{4+}$ species accounts for about $35.0 \%$. The presence of $\mathrm{V}^{4+}$ species is thought to be devoted to the oxidation process because it could improve the number of oxygen vacancies, which could promote the mobility of oxygen and enhance the redox ability [33].

In addition, XPS as surface analysis technique can be adopted to probe the surface compositions of these catalysts with the view of analyzing the diffusion of vanadium oxide on the zeolite surface. As Table 4 shows, the obvious decrease in the surface $\mathrm{V} /(\mathrm{Si}+\mathrm{Al})$ atomic ratios from 0.069 to 0.032 can be observed, which strongly demonstrates that vanadium oxide species have a better dispersion on hierarchical H-MOR obtained by post-synthesis treatment than that on $10 \% \mathrm{~V}_{2} \mathrm{O}_{5} / \mathrm{H}-\mathrm{MOR}$ catalyst [34]. The enhanced dispersion of vanadium oxide might have resulted from their larger mesopores volume, 
which could make better contact with the acid sites of zeolite and exert the synergistic effect of the bifunctional active sites.

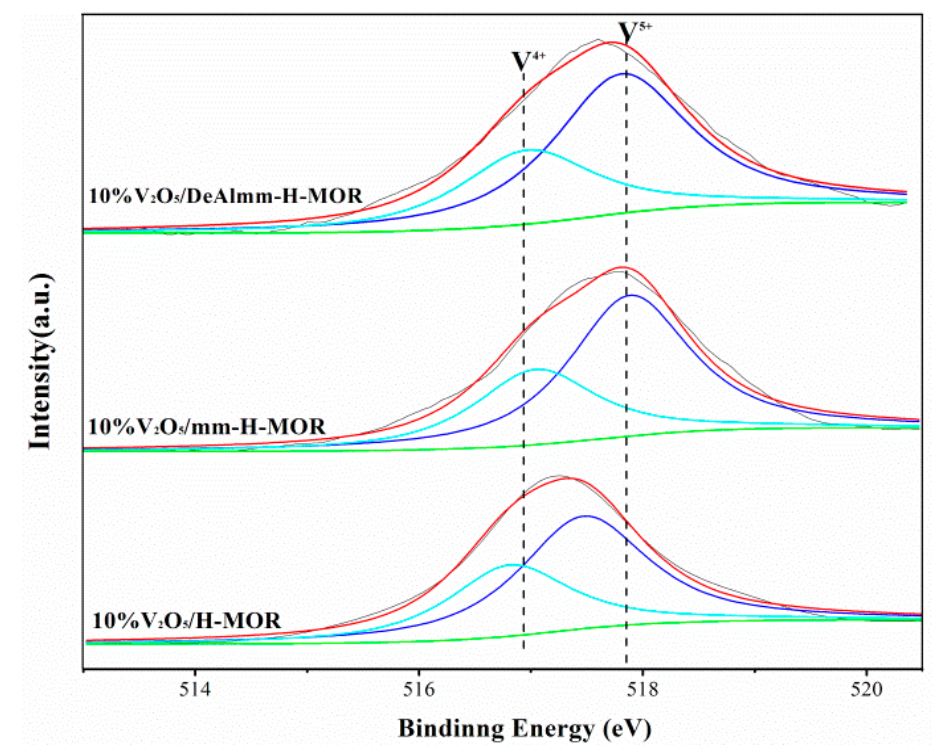

Figure 5. V2 $\mathrm{p}_{3 / 2} \mathrm{X}$-ray photoelectron spectra (XPS) spectra of post-synthesis H-MOR zeolites-supported vanadium oxide catalysts.

Table 4. X-ray photoelectron spectroscopy analysis for the post-synthesis H-MOR zeolites-supported vanadium oxide catalysts.

\begin{tabular}{cccccc}
\hline \multirow{2}{*}{ Samples } & \multirow{2}{*}{$\mathbf{V}(\mathbf{S i}+\mathbf{A l})$} & \multicolumn{3}{c}{$\mathbf{V}^{5+}$} & \multicolumn{3}{c}{$\mathbf{V}^{4+}$} & \\
\cline { 3 - 6 } & & $\mathbf{B E} / \mathbf{e v}$ & Area/\% & $\mathbf{B E} / \mathbf{e v}$ & Area/\% \\
\hline $10 \% \mathrm{~V}_{2} \mathrm{O}_{5} / \mathrm{H}-\mathrm{MOR}$ & 0.069 & 517.5 & 65.2 & 516.8 & 34.8 \\
$10 \% \mathrm{~V}_{2} \mathrm{O}_{5} / \mathrm{mm}-\mathrm{H}-\mathrm{MOR}$ & 0.055 & 517.9 & 64.9 & 517.1 & 35.1 \\
$10 \% \mathrm{~V}_{2} \mathrm{O}_{5} /$ deAlmm-H-MOR & 0.032 & 517.8 & 65.6 & 517.0 & 34.4 \\
\hline
\end{tabular}

\section{6. $\mathrm{H}_{2}-\mathrm{TPR}$}

Figure 6 shows the $\mathrm{H}_{2}$-TPR profiles of vanadium oxide supported on H-MOR zeolite after different treatments. It can be observed that there is an asymmetrical broad peak over each catalyst, where the former is attributed to the reduction of isolated vanadium species which are more easily reduced, and the latter is assigned to the reduction of polymeric VOx species [35]. As seen in Figure 6, it is noted that the reduction temperature for $10 \% \mathrm{~V}_{2} \mathrm{O}_{5} / \mathrm{mm}-\mathrm{H}-\mathrm{MOR}$ catalyst shifts to low temperature and the temperature of reduction peak for $10 \% \mathrm{~V}_{2} \mathrm{O}_{5} / \mathrm{deAlmm}-\mathrm{H}-\mathrm{MOR}$ catalyst decreases to much lower value compared with that of $10 \% \mathrm{~V}_{2} \mathrm{O}_{5} / \mathrm{H}-\mathrm{MOR}$ catalyst, which means that the reducibility of VOx species supported on the post-synthesis H-MOR zeolite is easier than that on H-MOR. The increased mesopores volume leads to the enhanced dispersion of vanadium oxide for the catalysts of $10 \% \mathrm{~V}_{2} \mathrm{O}_{5} / \mathrm{mm}-\mathrm{H}-\mathrm{MOR}$ and $10 \% \mathrm{~V}_{2} \mathrm{O}_{5} / \mathrm{deAlmm}-\mathrm{H}-\mathrm{MOR}$, which thus makes the reduction peak temperature shift to low value and indicates that the reducibility gets enhanced. This is consistent with the conclusion that the reducibility shows a direct relationship with the vanadia dispersion reported by Arena et al. [36]. The presence of mesopores is beneficial to the dispersion of VOx species, which therefore promotes the redox ability of supported catalysts and improves their catalytic performance of catalysts. 


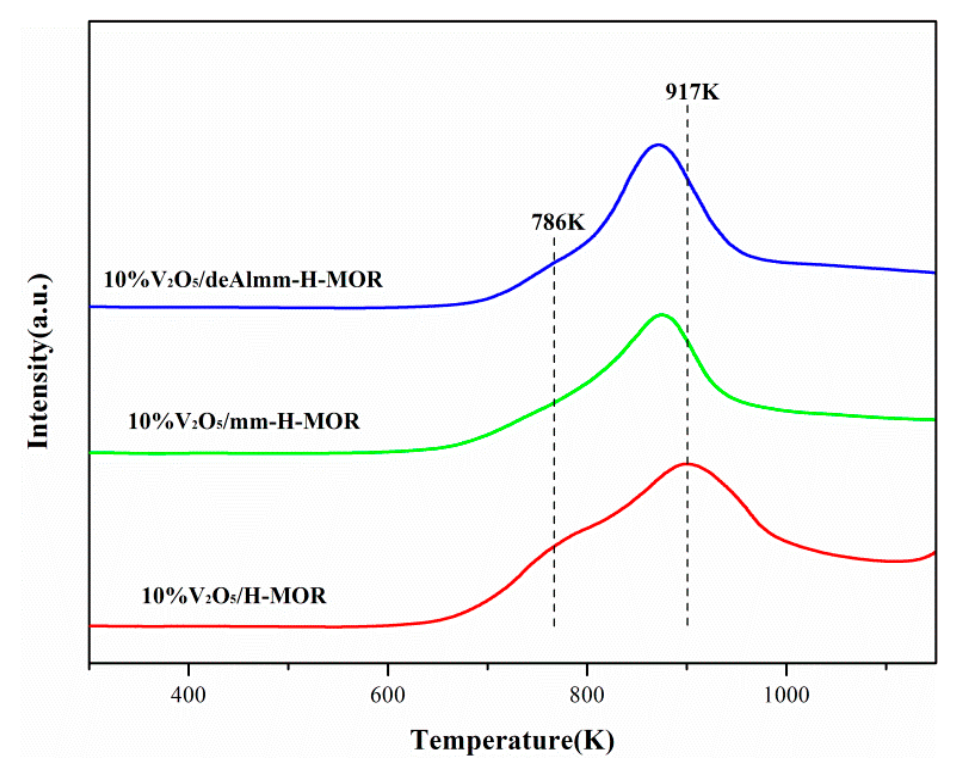

Figure 6. $\mathrm{H}_{2}$-TPR profiles for post-synthesis treatment H-MOR zeolites-supported vanadium oxide catalysts.

\subsection{FT-IR}

Figure 7 shows the FT-IR spectra of -OH group of the H-MOR zeolite and the supported H-MOR zeolite catalysts. It can be seen that there are four characteristic peaks of hydroxyl groups in the range of $3200-4000 \mathrm{~cm}^{-1}$ : the band at $3740 \mathrm{~cm}^{-1}$ is assigned to the vibrations of the isolated $\mathrm{Si}-\mathrm{OH}$ group on external crystal surface with the shoulder peak at $3727 \mathrm{~cm}^{-1}$ which belonged to the internal silanol groups; the band at $3595 \mathrm{~cm}^{-1}$ is corresponding to the bridging $\mathrm{Al}-\mathrm{OH}-\mathrm{Si}$ group; the band at $3653 \mathrm{~cm}^{-1}$ is ascribed to the Al-OH group [22]. As is presented in Figure 7, a significant increase in the intensity of the surface silanol groups accompanied with the reduction of internal $\mathrm{Si}-\mathrm{OH}$ group indirectly indicates the generation of mesopores since more silanol groups can be exposed due to the increased mesopores surfaces. For the alkaline treatment mm-H-MOR zeolite, the band at $3653 \mathrm{~cm}^{-1}$ shows higher intensity than that of parent MOR, it is related to the extra-framework $\mathrm{Al}$ species. The extra-framework $\mathrm{Al}$ species easily blocks the part of the channel structure and reduces the pore volume. The subsequent acid leaching of desilicated $\mathrm{H}-\mathrm{MOR}$ zeolite can effectively remove the extra-framework $\mathrm{Al}$ species in consistent with the ${ }^{27} \mathrm{Al}$ MAS NMR, which further increases the volume of mesopores [22]. It can also be evidenced that the intensity of Al-OH band at $3654 \mathrm{~cm}^{-1}$ for deAlmm-MOR sample is significantly reduced. In addition, it is clearly observed that the intensity of Al-OH-Si band at $3595 \mathrm{~cm}^{-1}$ has a notable increase upon the treatment of alkaline and alkaline-acid leaching in comparison with parent H-MOR.

After the loading of vanadium oxide on these post-synthesis zeolites, the difference in the intensity of -OH group for the supported catalysts is associated with the interaction between vanadium oxide species and surface hydroxyl group. The corresponding hydroxyl groups are reduced due to the overlap of the loaded component. The intensity of hydroxyl group for deAlmm-H-MOR zeolite-supported vanadium oxide is weaker than that of supported mm-H-MOR zeolite, which may be as a result of the difference in the dispersion of vanadium oxide. The degree of dispersion changes the interaction of VOx species with surface hydroxyl groups, which can effectively modulate the number of acid sites of supported catalysts. 


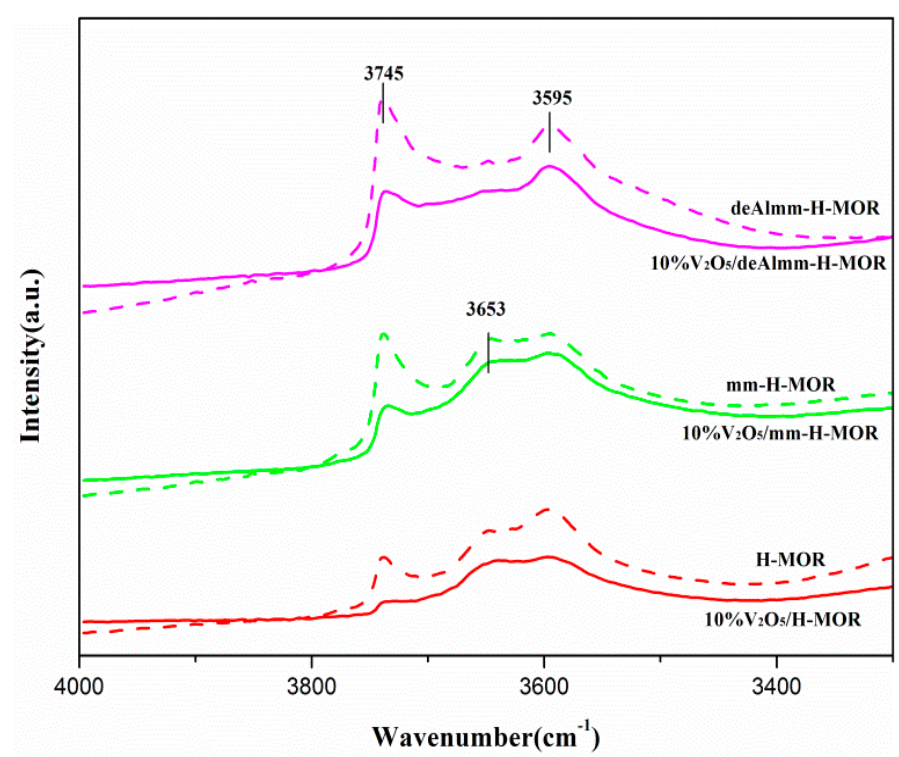

Figure 7. FT-IR spectra in the region of $-\mathrm{OH}$ stretching vibrations of post-synthesis treatment $\mathrm{H}-\mathrm{MOR}$ zeolites-supported vanadium oxide catalysts.

\subsection{Acid Property}

Figure $8 \mathrm{~A}$ presents the $\mathrm{NH}_{3}$-TPD profiles of $\mathrm{H}$-MOR zeolite-supported vanadium oxide after various treatments. The peak of $\mathrm{NH}_{3}$ desorption could be deconvoluted into three peaks with desorption temperature, which corresponds to weak acid, medium acid, and strong acid, respectively. As Table 5 shows, the acid concentration of $10 \% \mathrm{~V}_{2} \mathrm{O}_{5} / \mathrm{mm}-\mathrm{H}-\mathrm{MOR}$ after alkaline solution treatment increases obviously in comparison with the $10 \% \mathrm{~V}_{2} \mathrm{O}_{5} / \mathrm{H}-\mathrm{MOR}$ catalyst. It results from the decrease of molar $\mathrm{Si} / \mathrm{Al}$ ratio due to the selective $\mathrm{Si}$ atoms extraction. The pronounced increase in total acid content and strong acid sites is beneficial to the synthesis of DMMx, particularly for the longer C-O chain products according to our previous studies [37]. The subsequent acid leaching of desilicated MOR can effectively remove the extra-framework $\mathrm{Al}$ species formed by the alkaline solution treatment, resulting in a significant increase in the molar $\mathrm{Si} / \mathrm{Al}$ ratio from 7.4 to 18.8. Due to the decrease of $\mathrm{Al}$ content, the $10 \% \mathrm{~V}_{2} \mathrm{O}_{5} / \mathrm{deAlmm}-\mathrm{H}-\mathrm{MOR}$ catalyst has a decrease in total amount of acid sites. It can be seen that the change of weak acid sites is not obvious, while the obvious decrease in medium and strong acid sites is observed.

The acid type and concentration of the supported catalyst are also measured. On account of the part of Al-OH-Si groups situating in side-pockets inaccessible to pyridine molecule [38], the $\mathrm{NH}_{3}$ adsorption infrared spectra are more effective to investigate the acid type of the catalysts and the results are shown in Figure 8B. The absorption peaks at 1430 and $1620 \mathrm{~cm}^{-1}$ are corresponding to Brønsted and Lewis acid sites, respectively [31,39]. Quantitative analysis of Brønsted and Lewis acidity was performed using OMNIC infrared software and listed in Table 5. The number of Brønsted acid sites of the $10 \% \mathrm{~V}_{2} \mathrm{O}_{5} / \mathrm{mm}-\mathrm{H}-\mathrm{MOR}$ catalyst increases with the decrease of $\mathrm{Si} / \mathrm{Al}$ ratio and the reintegration of the part of $\mathrm{Al}$ in the desilication process. Meanwhile, the Lewis acidity also increases, which originates from the presence of a lot of extra-framework $\mathrm{Al}$ species in mm-H-MOR zeolite as measured by ${ }^{27} \mathrm{Al}$ MAS NMR. The variations on the acid sites are in consistent with the changes of the hydroxyl groups of the catalysts. For $10 \% \mathrm{~V}_{2} \mathrm{O}_{5} / \mathrm{deAlmm}-\mathrm{H}-\mathrm{MOR}$ catalyst, the removal of extra-framework $\mathrm{Al}$ species by mild acid leaching treatment reduces the amount of Lewis acid sites, and the Brønsted acid sites also decrease concurrently with the increase of $\mathrm{Si} / \mathrm{Al}$ ratio. However, the number of acid sites is both still higher than those of $10 \% \mathrm{~V}_{2} \mathrm{O}_{5} / \mathrm{H}-\mathrm{MOR}$, which maybe because of the newly formed hydroxyl groups or more exposed hydroxyl groups owe to the post-synthesis treatments (Figure S2). However, for the ratio of Brønsted/Lewis acid sites, it is observed to be decreased to 1.02. 

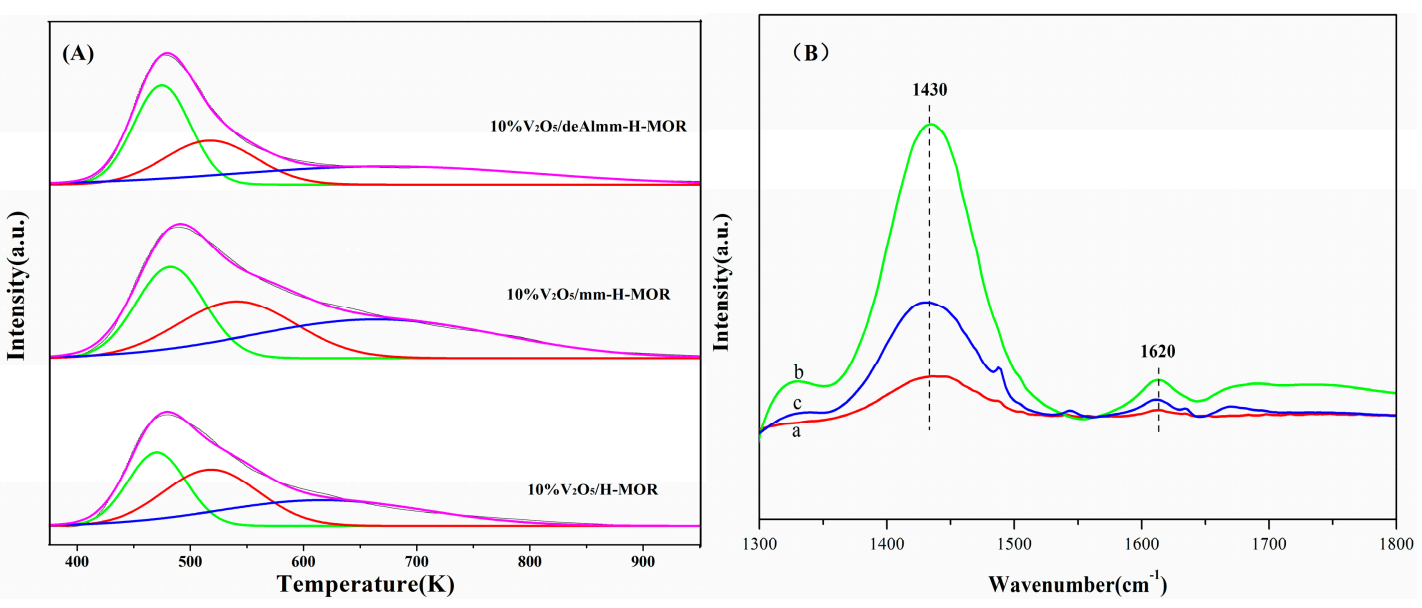

Figure 8. (A) $\mathrm{NH}_{3}$-TPD profiles of post-synthesis H-MOR zeolites-supported vanadium oxide catalysts and (B) $\mathrm{NH}_{3}$-IR profiles of catalysts (a) $10 \% \mathrm{~V}_{2} \mathrm{O}_{5} / \mathrm{H}-\mathrm{MOR}$, (b) $10 \% \mathrm{~V}_{2} \mathrm{O}_{5} / \mathrm{mm}-\mathrm{H}-\mathrm{MOR}$, (c) $10 \% \mathrm{~V}_{2} \mathrm{O}_{5} / \mathrm{deAlmm}-\mathrm{H}-\mathrm{MOR}$.

Table 5. Acidity property of $10 \% \mathrm{~V}_{2} \mathrm{O}_{5}$ supported on $\mathrm{H}-\mathrm{MOR}$ zeolites catalysts prepared by post-synthesis treatment.

\begin{tabular}{|c|c|c|c|c|c|c|c|c|}
\hline \multirow{2}{*}{ Catalysts } & \multicolumn{4}{|c|}{$\mathrm{NH}_{3}$-TPD } & \multicolumn{4}{|c|}{$\mathrm{NH}_{3}$-IR } \\
\hline & WAS $^{a}$ & MAS $^{b}$ & SAS $^{\mathrm{c}}$ & Total $^{\mathrm{d}}$ & $\mathrm{B}^{\mathrm{e}}$ & $L^{f}$ & Total $\mathrm{g}$ & $B / L^{h}$ \\
\hline $10 \% \mathrm{~V}_{2} \mathrm{O}_{5} / \mathrm{H}-\mathrm{MOR}$ & $\begin{array}{l}0.092 \\
(470)\end{array}$ & $\begin{array}{l}0.116 \\
(518)\end{array}$ & $\begin{array}{l}0.113 \\
(617)\end{array}$ & 0.321 & 64.2 & 47.5 & 111.7 & 1.35 \\
\hline $10 \% \mathrm{~V}_{2} \mathrm{O}_{5} / \mathrm{mm}-\mathrm{H}-\mathrm{MOR}$ & $\begin{array}{l}0.127 \\
(481)\end{array}$ & $\begin{array}{l}0.133 \\
(540)\end{array}$ & $\begin{array}{l}0.192 \\
(663)\end{array}$ & 0.452 & 359.2 & 239.4 & 598.6 & 1.50 \\
\hline $10 \% \mathrm{~V}_{2} \mathrm{O}_{5} / \mathrm{deAlmm}-\mathrm{H}-\mathrm{MOR}$ & $\begin{array}{l}0.106 \\
(473)\end{array}$ & $\begin{array}{l}0.075 \\
(516)\end{array}$ & $\begin{array}{l}0.103 \\
(671)\end{array}$ & 0.285 & 173.1 & 168.9 & 342.0 & 1.02 \\
\hline
\end{tabular}

${ }^{\mathrm{a}}$ Weak acid sites (mmol/g). ${ }^{\mathrm{b}}$ Medium acid sites (mmol/g). ${ }^{\mathrm{c}}$ Strong acid sites $(\mathrm{mmol} / \mathrm{g}) .{ }^{\mathrm{d}}$ Total acid sites. ${ }^{\mathrm{e}}$ Brønsted acid $(\mu \mathrm{mol} / \mathrm{g})$. ${ }^{\mathrm{f}}$ Lewis acid $(\mu \mathrm{mol} / \mathrm{g}) .{ }^{\mathrm{g}}$ Total acid sites $(\mu \mathrm{mol} / \mathrm{g}) .{ }^{\mathrm{h}}$ The ratio of Brønsted acid and Lewis acid.

\subsection{Catalytic Performance}

Table 6 shows the catalytic performance of vanadium oxide supported on post-synthesis $\mathrm{H}-\mathrm{MOR}$ and parent $\mathrm{H}-\mathrm{MOR}$ on the oxidation products distribution for DME direct oxidation. When $10 \% \mathrm{~V}_{2} \mathrm{O}_{5} / \mathrm{H}-\mathrm{MOR}$ is used as catalyst, the conversion of DME is $14.4 \%$, and the DMMx selectivity reaches $60.0 \%$. However, the by-product dominated by CO is observed to be as high as $20.4 \%$. Due to the diffusion limitations of the intermediate or products by the 8-membered ring in H-MOR zeolite, the formed DMM is thought to be suffered from the mass constraints to lead to the disproportionation reaction to synthesize DME and methyl formate (MF), and then the formed MF could possibly decompose to $\mathrm{CO}$ and $\mathrm{CH}_{3} \mathrm{OH}$, which thus results in the high selectivity to $\mathrm{CO}$ and decreases the selectivity of target products [11].

$$
\begin{gathered}
2 \mathrm{CH}_{3} \mathrm{OCH}_{2} \mathrm{OCH}_{3} \rightarrow 2 \mathrm{CH}_{3} \mathrm{OCH}_{3}+\mathrm{HCOOCH}_{3}, \Delta \mathrm{G}^{\circ}=-72.3 \mathrm{KJ} \cdot \mathrm{mol}^{-1} \\
\mathrm{HCOOCH}_{3} \rightarrow \mathrm{CO}+\mathrm{CH}_{3} \mathrm{OH}, \Delta \mathrm{G}^{\circ}=+0.4 \mathrm{KJ} \cdot \mathrm{mol}^{-1}
\end{gathered}
$$

Compared with $10 \% \mathrm{~V}_{2} \mathrm{O}_{5} / \mathrm{H}-\mathrm{MOR}$, a larger mesopores volume and a broader pore size for $10 \% \mathrm{~V}_{2} \mathrm{O}_{5} / \mathrm{mm}-\mathrm{H}-\mathrm{MOR}$ is obtained, which could enhance the accessibility of bifunctional sites and exert synergistic effect. More importantly, it effectively promotes the diffusion of intermediates or products to hinder the disproportionation of DMM and the decomposition of MF. Besides, the desilication of H-MOR zeolite facilitates the increase of acid sites. On the other hand, it improves the redox ability resulted from the enhanced dispersion of vanadium oxide species. These are devoted to the improvement of DMMx selectivity to $72.5 \%$ from $60.0 \%$. The $\mathrm{DMM}_{2-3}$ products only have a very slight increase, while an obvious drop on the selectivity to CO is observed from $20.1 \%$ to $9.4 \%$. After 
the mild-acid leaching treatment of mm-MOR, a further increase in the mesopores volume due to the removal of extra-framework $\mathrm{Al}$ species blocking the channel structure can be achieved and the catalytic performance of $10 \% \mathrm{~V}_{2} \mathrm{O}_{5} / \mathrm{deAlmm}-\mathrm{H}-\mathrm{MOR}$ is further promoted as expected. The selectivity of DMMx increases from $72.5 \%$ to $78.2 \%$, meanwhile, the $\mathrm{DMM}_{2-3}$ selectivity slightly increases to $28.1 \%$ from $22.6 \%$. Especially, more interesting, $\mathrm{CO}$ selectivity drops to zero. It is considered that the superior catalytic performance for $10 \% \mathrm{~V}_{2} \mathrm{O}_{5} / \mathrm{deAlmm}-\mathrm{H}-\mathrm{MOR}$ catalyst is extremely associated with larger mesopores volume generated by alkaline and acid leaching treatment. The stability evaluation and regeneration of catalysts have been carried out on $10 \% \mathrm{~V}_{2} \mathrm{O}_{5} / \mathrm{deAlmm}-\mathrm{H}-\mathrm{MOR}$ (Figure S4). The conversion of DME shows a continuous decrease during $10 \mathrm{~h}$, but the DMMx selectivity changes slightly and stabilizes at about $77 \%$. The spent catalyst was calcined at $773 \mathrm{~K}$ in the atmosphere of $\mathrm{O}_{2}$ for $1 \mathrm{~h}$ and the catalytic performance can be recovered to that of the fresh catalyst. We infer that carbonaceous deposit may be the main reason for the catalyst deactivation.

The acid sites and redox sites are known as crucial parameters for the DMMx formation from DME oxidation. However, in this work, we find that the pore structure of support also plays an important role in products distribution for DME direct oxidation. For the $10 \% \mathrm{~V}_{2} \mathrm{O}_{5} / \mathrm{H}-\mathrm{MOR}$ catalyst, it is considered to be favorable to the formation of DMMx due to the good redox ability and a high Brønsted/Lewis acid sites (B/L) ratio. However, the DMMx selectivity is $60.0 \%$ with high CO selectivity of $20.4 \%$. Due to the presence of 8-MR, DMMx products formed on the acid sites located in 8-MR (Figure S3) are hindered by the diffusion constraints to lead to the occurrence of DMM disproportionation and the decomposition of formed MF, which results in the formation of more CO by-product. After the alkaline treatments, TEM characterization (Figure 2b) demonstrates directly that the mesopores structure is successfully introduced into $\mathrm{H}-\mathrm{MOR}$ and the mesopores volume for $10 \% \mathrm{~V}_{2} \mathrm{O}_{5} / \mathrm{mm}-\mathrm{H}-\mathrm{MOR}$ reaches $0.110 \mathrm{~cm}^{3} \cdot \mathrm{g}^{-1}$. The obvious decrease in the surface vanadium atomic density from 0.069 to 0.055 is observed, which indicates the better dispersion of supported vanadium oxide species on the post-synthesis H-MOR zeolites. The enhanced dispersion can effectively promote the redox ability to involve in the oxidation process, and could also make better contact with the acid sites of zeolite to exert the synergistic effect of the bifunctional active sites. In addition, $10 \% \mathrm{~V}_{2} \mathrm{O}_{5} / \mathrm{mm}-\mathrm{H}-\mathrm{MOR}$ has an obvious increase in the ratio of $\mathrm{B} / \mathrm{L}$ and the number of acid sites due to the decrease of $\mathrm{Si} / \mathrm{Al}$ ratio resulted from the extraction of silicon atom and the reintegration of the part of $\mathrm{Al}$ confirmed by the NMR characterizations. Upon the desilication treatment, the promotion of redox capability is beneficial to the transformation of methoxy group (derived from the dissociation of $\mathrm{CH}_{3} \mathrm{OCH}_{3}$ ) to $\mathrm{HCHO}$, and the increases of acid sites and $\mathrm{B} / \mathrm{L}$ ratio are advantageous for the synthesis of $\mathrm{DMM}$ by the acetalization of $\mathrm{HCHO}$ with the near methoxy species or the free methanol molecule. More importantly, the existence of mesopores can effectively shorten the length of the 12-ring main channels and open the side 8-ring channel pockets, which can increase the distance between DMM molecules and decrease the contact probability to inhibit the secondary reaction as shown in Figure 9. The DMM molecule can easily desorb to gas phase or combine $\mathrm{CH}_{3} \mathrm{O}$ groups to form $\mathrm{DMM}_{2}$ and the longer $\mathrm{C}-\mathrm{O}$ chain products $[7,9,37]$. Thus, the DMMx selectivity improved up to $72.5 \%$ with an obvious drop of $\mathrm{CO}$. For $10 \% \mathrm{~V}_{2} \mathrm{O}_{5} / \mathrm{deAlmm}-\mathrm{H}-\mathrm{MOR}$ catalysts, the number of acid sites and $\mathrm{B} / \mathrm{L}$ ratio decreased compared with $10 \% \mathrm{~V}_{2} \mathrm{O}_{5} / \mathrm{mm}-\mathrm{H}-\mathrm{MOR}$, which shows a negative effect on DMMx synthesis. However, the DMMx selectivity is increased up to $78.2 \%$ instead and no $\mathrm{CO}$ is formed. The experimental results further demonstrate that the transport limitation can be eliminated due to the larger mesopores volume and wider pore size. The presence of mesopores structure plays a leading role in the difference of product distribution from DME direct oxidation. 
Table 6. Effects of mesopores on the catalytic performance of $10 \% \mathrm{~V}_{2} \mathrm{O}_{5} / \mathrm{H}-\mathrm{MOR}$ and post-synthesis zeolites-supported vanadium catalysts for DME oxidation.

\begin{tabular}{cccccccccccc}
\hline \multirow{2}{*}{$\begin{array}{c}\text { Catalysts } \\
\end{array}$} & DME & \multicolumn{10}{c}{ Selectivity (C-mol\%) } \\
\cline { 3 - 13 } & Conv. (\%) & DMM $_{\mathbf{1 - 3}}$ & $\mathbf{D M M}$ & $\mathbf{D M M}_{\mathbf{2}}$ & $\mathbf{D M M}_{\mathbf{3}}$ & $\mathbf{H C H O}$ & $\mathbf{M F}$ & $\mathbf{C H}_{\mathbf{3}} \mathbf{O H}$ & $\mathbf{C O}$ & $\mathbf{C O}_{\mathbf{2}}$ & $\mathbf{C H}_{\mathbf{4}}$ \\
\hline $10 \% \mathrm{~V}_{2} \mathrm{O}_{5} / \mathrm{H}-\mathrm{MOR}$ & 14.4 & 60.0 & 37.4 & 20.4 & 2.2 & 3.2 & 4.2 & 12.1 & 20.4 & 0 & 0 \\
$10 \% \mathrm{~V}_{2} \mathrm{O}_{5} / \mathrm{mm}-\mathrm{m}-\mathrm{MOR}$ & 11.2 & 72.5 & 49.0 & 22.0 & 1.5 & 0.8 & 6.1 & 11.3 & 9.4 & 0 & 0 \\
\hline $10 \% \mathrm{~V}_{2} \mathrm{O}_{5} /$ deAlmm-H-MOR & 10.6 & 78.2 & 50.1 & 26.8 & 1.3 & 0.4 & 6.8 & 14.7 & 0 & 0 & 0 \\
\hline
\end{tabular}

Reaction conditions: $\mathrm{T}=503 \mathrm{~K}$, atmospheric pressure, GHSV $=3600 \mathrm{~h}^{-1}, \mathrm{O}_{2} / \mathrm{DME}$ molar ratio $=1$. DMM: $\mathrm{CH}_{3} \mathrm{OCH}_{2} \mathrm{OCH}_{3}, \mathrm{DMM}_{2}: \mathrm{CH}_{3} \mathrm{O}\left(\mathrm{CH}_{2} \mathrm{O}\right)_{2} \mathrm{CH}_{3}, \mathrm{DMM}_{3}: \mathrm{CH}_{3} \mathrm{O}\left(\mathrm{CH}_{2} \mathrm{O}\right)_{3} \mathrm{CH}_{3}, \mathrm{MF}: \mathrm{HCOOCH}_{3}$.

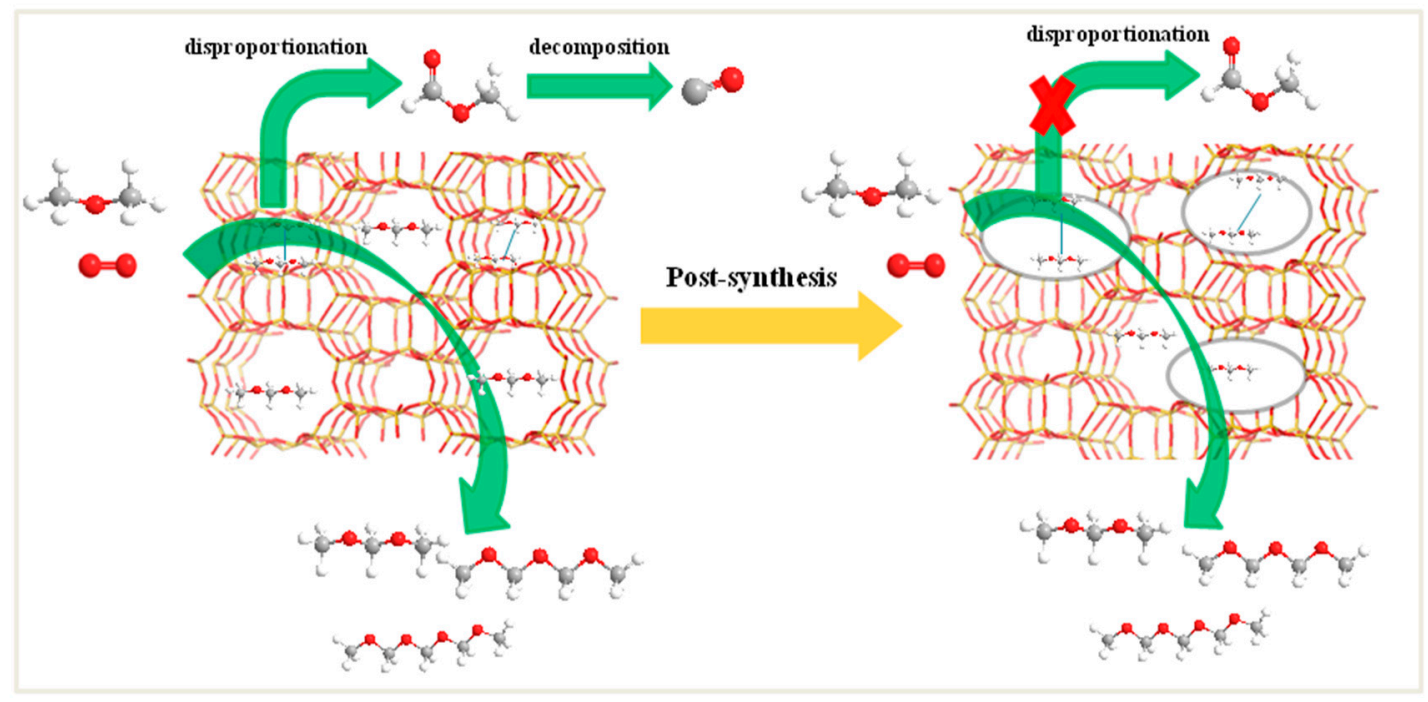

Figure 9. The formation of DMMx from DME oxidation over VOx supported on H-MOR and post-synthesis H-MOR catalysts.

\section{Experimental}

\subsection{Catalysts Preparation}

$\mathrm{H}-\mathrm{MOR}$ with $\mathrm{Si} / \mathrm{Al}=9.6$ was provided by Nankai University Catalyst Co. Ltd. The mm-H-MOR zeolites were prepared by post-synthesis method with alkaline solutions ( $30 \mathrm{~mL} 0.2 \mathrm{M} \mathrm{NaOH}$ per $1 \mathrm{~g}$ mordenite stirred in a beaker at $358 \mathrm{~K}$ for $2 \mathrm{~h}$ ), ion-exchanged with $0.5 \mathrm{M} \mathrm{NH}_{4} \mathrm{NO}_{3}$ solution at room temperature for $12 \mathrm{~h}$ over three times, and calcined at $823 \mathrm{~K}$ for $5 \mathrm{~h}$. For deAlmm-H-MOR zeolite, it is first treated by alkaline solutions $(30 \mathrm{~mL} 0.2 \mathrm{M} \mathrm{NaOH}$ per $1 \mathrm{~g}$ mordenite stirred in a beaker at $358 \mathrm{~K}$ for $2 \mathrm{~h})$ and subsequently with acid solution $(100 \mathrm{~mL} 0.5 \mathrm{M}$ oxalic acid per $1 \mathrm{~g}$ alkaline-treated zeolite stirred in a beaker at $353 \mathrm{~K}$ for $20 \mathrm{~h}$ ). Finally, the obtained zeolites were ion-exchanged with $0.5 \mathrm{M}$ $\mathrm{NH}_{4} \mathrm{NO}_{3}$ solution at room temperature for $12 \mathrm{~h}$ over three times and calcined at $823 \mathrm{~K}$ for $5 \mathrm{~h}$.

MOR in the $\mathrm{H}^{+}$form was impregnated with an aqueous solution of $\mathrm{NH}_{4} \mathrm{VO}_{3}$ dissolved in oxalic acid solution and still stood at ambient temperature for $10 \mathrm{~h}$, dried overnight at $383 \mathrm{~K}$ and finally calcined at the temperature of $773 \mathrm{~K}$ for $5 \mathrm{~h}$ in static air to obtain $\mathrm{V}_{2} \mathrm{O}_{5} / \mathrm{H}-\mathrm{MOR}\left(10 \mathrm{wt} . \% \mathrm{~V}_{2} \mathrm{O}_{5}\right)$.

\subsection{Catalyst Characterization}

X-ray diffraction (XRD) measurements were carried out on a Bruker D2 phaser X-ray Diffractometer (Bruker, Karlsruhe, Germany) in the range of $5-70^{\circ}$ and the scan rate of $4^{\circ} / \mathrm{min}$ using $\mathrm{Cu} \mathrm{K} \alpha$ radiation source.

BET surface area and pore volume of the samples were determined by $\mathrm{N}_{2}$ adsorption-desorption at $77 \mathrm{~K}$ in Micromeritics TriStar II 3020 equipment (Atlanta, GA, USA). 
Transmission electron microscopy (TEM) was performed on a JEM-2100 electron microscope (JEOL Company, Tokyo, Japan).

Solid-state ${ }^{27} \mathrm{Al}$ and ${ }^{29} \mathrm{Si}$ MAS NMR experiments were carried out on the Bruker Avance III $600 \mathrm{MHz}$ spectrometer (Bruker, Karlsruhe, Germany). The relaxation delay of $20 \mathrm{~s}$ and the rotation speed of $10 \mathrm{kHz}$ were employed for measurement of the ${ }^{29} \mathrm{Si}$ MAS NMR and ${ }^{27} \mathrm{Al}$ MAS NMR spectra. The chemical shifts were referenced to the kaoline at $-91.5 \mathrm{ppm}$ and TMS at $0 \mathrm{ppm}$. The framework aluminum content $\left(\mathrm{Si} / \mathrm{Al}_{\mathrm{FR}}\right)$ was estimated from the intensity of the ${ }^{29} \mathrm{Si} \mathrm{NMR}$ resonances according to the equation $\mathrm{Si} / \mathrm{Al}_{\mathrm{FR}}=\mathrm{I} / 0.25 \mathrm{I}_{1}$, where $\mathrm{I}$ and $\mathrm{I}_{1}$ are corresponding to the intensity of $\mathrm{Si}(4 \mathrm{Si}, 0 \mathrm{Al}), \mathrm{Si}(3 \mathrm{Si}$, $1 \mathrm{Al})$, respectively.

X-ray photoelectron spectra (XPS) were measured on Kratos Axis Ultra Dld spectrometer (Kratos, Manchester, $\mathrm{UK}$ ) equipped with $\mathrm{Al}$ anode $(\mathrm{Al} \mathrm{K} \alpha \mathrm{h} v=1486.6 \mathrm{eV})$ powered at $150 \mathrm{~W}$.

FT-IR measurements were recorded with Bruker Tensor 27 (Bruker, Karlsruhe, Germany) in the range of 4000-600 $\mathrm{cm}^{-1}$ with a resolution of $2 \mathrm{~cm}^{-1}$ and using 64 scans. The samples were pretreated at the temperature of $673 \mathrm{~K}$ under the Ar atmosphere before measuring.

$\mathrm{NH}_{3}$-TPD profiles were obtained in the TP-5080 type automatic adsorption instrument from Tianjin XianQuan Co. Ltd (Tianjin, China). In all experiments, $100 \mathrm{mg}$ of sample was pretreated at $673 \mathrm{~K}$ under $\mathrm{N}_{2}$ flow $(30 \mathrm{~mL} / \mathrm{min})$ for $1 \mathrm{~h}$, then cooled down to $373 \mathrm{~K}$. At this temperature, $\mathrm{NH}_{3}$ was introduced into the flow system until saturation and the excess ammonia were removed with $\mathrm{N}_{2}$ at 373 $\mathrm{K}$ for $1 \mathrm{~h}$. Finally, the $\mathrm{NH}_{3}$-TPD profiles were recorded from $373 \mathrm{~K}$ to $973 \mathrm{~K}$ at a rate of $10 \mathrm{~K} / \mathrm{min}$ with a thermal conductivity detector (TCD).

$\mathrm{NH}_{3}$-Fourier transform infrared $\left(\mathrm{NH}_{3}\right.$-IR) spectrometer was detected on the Nicolet 6700 instrument (Thermo scientific, USA) equipped with a MCT detector. The catalysts were pressed into thin self-supported wafers and placed in a sample cell coupled to a vacuum line and evacuated in situ at $473 \mathrm{~K}$ for $30 \mathrm{~min}$. Then the temperature was cooled down to $313 \mathrm{~K}, \mathrm{NH}_{3}$ molecules were absorbed on the catalysts. The excess $\mathrm{NH}_{3}$ molecules were desorbed under vacuum at $423 \mathrm{~K}$ for $30 \mathrm{~min}$ and afterwards the spectra were recorded. The extinction coefficient for the $\mathrm{NH}_{4}{ }^{+}$band was $13.5 \mathrm{~cm}^{2} \cdot \mu \mathrm{mol}^{-1}$ with $0.9 \mathrm{~cm}^{2} \cdot \mu \mathrm{mol}^{-1}$ for $\mathrm{NH}_{3} \mathrm{~L}$ band [31].

$\mathrm{H}_{2}$-temperature programmed reduction $\left(\mathrm{H}_{2}\right.$-TPR) measurements were taken by using TP-5080 type automatic adsorption instrument with a thermal conductivity detector (TCD) in Tianjin XianQuan Co. Ltd. In all experiments, $50 \mathrm{mg}$ of sample was first treated at $673 \mathrm{~K}$ under $\mathrm{N}_{2}$ flow $(30 \mathrm{~mL} / \mathrm{min})$ for $1 \mathrm{~h}$, then cooled down to $303 \mathrm{~K}$, the TPR measurement was conducted using $10 \% \mathrm{H}_{2} / \mathrm{N}_{2}$ mixture, and the $\mathrm{H}_{2}$-TPR profiles were recorded from $303 \mathrm{~K}$ to $1123 \mathrm{~K}$ at a rate of $10 \mathrm{~K} / \mathrm{min}$.

\subsection{Catalytic Reaction}

The catalytic reaction was carried out in a continuous flow type fixed-bed reactor with the feedstock of DME and $\mathrm{O}_{2}$ which the molar ratio between them was 1 . The catalyst ( $1 \mathrm{~mL}, 20-40$ mesh) was mixed with ground quartz at an identical volume to prevent overheating of the catalyst due to exothermic reaction. The catalyst was pretreated in flow of $\mathrm{O}_{2}(30 \mathrm{~mL} / \mathrm{min})$ before reaction. The reaction products were analyzed by GC-2014CPF/SPL (Shimadzu Co., Kyoto, Japan) equipped with flame ionization detector $(60 \mathrm{~m} \times 0.25 \mathrm{~mm}$, DB-1, Agilent Technologies Inc., Palo Alto, IA, USA), GC-2014 (Shimadzu Co., Kyoto, Japan)with thermal conductivity detector (Porapak T column, Waters Corporation, Milford, MA, USA), and GC-4000A (TDX-01 column, East\&West Analytical Instruments, Inc., Beijing, China) with thermal conductivity detectors. The carbon balances of most experiments were within $95-99 \%$.

\section{Conclusions}

In summary, hierarchical H-MOR zeolites have been successfully fabricated by alkaline and alkaline-acid treatment strategy. VOx species supported on post-synthesis H-MOR zeolites are used for the direct oxidation of DME. The creation of mesopores structure for $10 \% \mathrm{~V}_{2} \mathrm{O}_{5} / \mathrm{deAlmm}-\mathrm{H}-\mathrm{MOR}$ catalyst can effectively increase the DMMx selectivity up to $78.2 \%$ and suppress the formation of $\mathrm{CO}$. A large 
amount of intra-crystal mesopores could facilitate the mass transfer to avoid the secondary reaction and also promote the contact of the reactants with the active sites. Furthermore, the mesopores structure can effectively enhance the dispersion of vanadium oxide to improve the redox ability of supported catalysts. Although the decreased strong acid sites and $\mathrm{B} / \mathrm{L}$ ratio for $10 \% \mathrm{~V}_{2} \mathrm{O}_{5} / \mathrm{deAlmm}-\mathrm{H}-\mathrm{MOR}$ catalyst present the adverse impact, it exhibits the highest catalytic performance for the synthesis of DMMx due to its largest mesopores volume compared with $10 \% \mathrm{~V}_{2} \mathrm{O}_{5} / \mathrm{H}-\mathrm{MOR}$ and $10 \% \mathrm{~V}_{2} \mathrm{O}_{5} / \mathrm{mm}-\mathrm{H}-\mathrm{MOR}$ catalysts. It strongly corroborates that the mesopores structure in the zeolite is very important in the synthesis of DMMx from DME direct oxidation.

Supplementary Materials: The following are available online at http://www.mdpi.com/2073-4344/9/7/628/s1, Figure S1: FT-IR spectra of vanadium oxide supported on post-synthesis H-MOR zeolites, Figure S2: FT-IR spectra of adsorption of $\mathrm{NH}_{3}$ on different catalysts with details of the $\mathrm{OH}$ region, Figure S3: FT-IR spectra of the $\mathrm{OH}$ stretching region of the $10 \% \mathrm{~V}_{2} \mathrm{O}_{5} / \mathrm{H}-\mathrm{MOR}$ and $\mathrm{H}-\mathrm{MOR}$, Figure S4: Catalytic performance of DME direct oxidation to DMMx over $10 \% \mathrm{~V}_{2} \mathrm{O}_{5} /$ deAlmm-H-MOR during $10 \mathrm{~h}$ on stream at the conditions of $503 \mathrm{~K}$, atmospheric pressure, $\mathrm{O}_{2} /$ DME molar ratio $=1$, and GHSV of $3600 \mathrm{~h}^{-1}$, Table S1: Relative peak areas determined from ${ }^{27} \mathrm{Al}$ MAS NMR.

Author Contributions: Catalysts preparation, catalyst characterization, and catalyst evaluation were done by W.W. under the supervision of Q.Z., and Y.T. Both authors contributed to the data analysis and manuscript preparation. All authors have given approval for the final version of the manuscript.

Funding: This research was funded by the National Natural Science Foundation of China (No. 21773283, 21373253), CAS Interdisciplinary Innovation Team (No. BK2018001), and the Youth Innovation Promotion Association CAS (No. 2014155).

Acknowledgments: This work was supported by the National Natural Science Foundation of China (No. 21773283, 21373253), CAS Interdisciplinary Innovation Team (No. BK2018001), and the Youth Innovation Promotion Association CAS (No. 2014155).

Conflicts of Interest: The authors declare no conflict of interest.

\section{References}

1. Sánchez-Contador, M.; Ateka, A.; Aguayo, A.T.; Bilbao, J. Effects of diesel/PODE (polyoxymethylene dimethyl ethers) blends on combustion and emission characteristics in a heavy duty diesel engine. Fuel Process. Technol. 2018, 179, 258-268. [CrossRef]

2. Song, F.; Tan, Y.; Xie, H.; Zhang, Q.; Han, Y. Direct synthesis of dimethyl ether from biomass-derived syngas over $\mathrm{Cu}-\mathrm{ZnO}-\mathrm{Al}_{2} \mathrm{O}_{3}-\mathrm{ZrO}_{2}(\mathrm{x}) / \gamma-\mathrm{Al}_{2} \mathrm{O}_{3}$ bifunctional catalysts: Effect of $\mathrm{Zr}$-loading. Fuel Process. Technol. 2014, 126, 88-94. [CrossRef]

3. Liu, F.; Wang, T.; Zheng, Y.; Wang, J. Synergistic effect of Brønsted and Lewis acid sites for the synthesis of polyoxymethylene dimethyl ethers over highly efficient $\mathrm{SO}_{4}{ }^{2}-/ \mathrm{TiO}_{2}$ catalysts. J. Catal. 2017, 355, 17-25. [CrossRef]

4. Liu, J.; Wang, H.; Li, Y.; Zheng, Z.; Xue, Z.; Shang, H.; Yao, M. Effects of diesel/PODE (polyoxymethylene dimethyl ethers) blends on combustion and emission characteristics in a heavy duty diesel engine. Fuel 2016, 177, 206-216. [CrossRef]

5. Qi, J.G.; Hu, Y.F.; Niu, J.G.; Ma, W.T.; Jiang, S.Q.; Wang, Y.C.; Zhang, X.M.; Zhang, Y.H. Evaluation of polyoxymethylene dimethyl ethers as a new type of diesel additives. Fuel 2018, 234, 135-141. [CrossRef]

6. Baranowski, C.J.; Bahmanpour, A.M.; Kröcher, O. Catalytic synthesis of polyoxymethylene dimethyl ethers (OME): A review. Appl. Catal. B Environ. 2017, 217, 407-420. [CrossRef]

7. Liu, H.C.; Iglesia, E. Selective one-step synthesis of dimethoxymethane via methanol or dimethyl ether oxidation on $\mathrm{H}_{3}+{ }_{n} \mathrm{~V}_{\mathrm{n}} \mathrm{Mo}_{12}{ }_{n} \mathrm{PO}_{40}$ keggin structures. J. Phys. Chem. B 2003, 107, 10840-10847. [CrossRef]

8. Tsubaki, N.; Zhang, Q.; Wang, W.; Bai, Y.; Han, Y.; Tan, Y. Application of modified CNTs with Ti( $\left(\mathrm{SO}_{4}\right)_{2}$ in selective oxidation of dimethyl ether. Catal. Sci. Technol. 2016, 6, 7193-7202.

9. Zhang, Q.D.; Tan, Y.S.; Liu, G.B.; Zhang, J.F.; Han, Y.Z. Rhenium oxide-modified $\mathrm{H}_{3} \mathrm{PW}_{12} \mathrm{O}_{40} / \mathrm{TiO}_{2}$ catalysts for selective oxidation of dimethyl ether to dimethoxy dimethyl ether. Green Chem. 2014, 16, 4708-4715. [CrossRef]

10. Gao, X.J.; Wang, W.F.; Gu, Y.Y.; Zhang, Z.Z.; Zhang, J.F.; Zhang, Q.D.; Tsubaki, N.; Han, Y.Z.; Tan, Y.S. Synthesis of polyoxymethylene dimethyl ethers from dimethyl ether direct oxidation over carbon-based catalysts. Chem CatChem 2018, 10, 273-279. [CrossRef] 
11. Celik, F.E.; Kim, T.J.; Bell, A.T. Effect of zeolite framework type and Si/Al ratio on dimethoxymethane carbonylation. J. Catal. 2010, 270, 185-195. [CrossRef]

12. Zhang, Q.; Wang, W.; Zhang, Z.; Han, Y.; Tan, Y. Low-Temperature Oxidation of Dimethyl Ether to Polyoxymethylene Dimethyl Ethers over CNT-Supported Rhenium Catalyst. Catalysts 2016, 6, 43. [CrossRef]

13. Zhang, Q.D.; Tan, Y.S.; Yang, C.H.; Han, Y.Z. $\mathrm{MnCl}_{2}$ modified $\mathrm{H}_{4} \mathrm{SiW}_{12} \mathrm{O}_{40} / \mathrm{SiO}_{2}$ catalysts for catalytic oxidation of dimethy ether to dimethoxymethane. J. Mol. Catal. A Chem. 2007, 263, 149-155. [CrossRef]

14. Zhang, Q.D.; Tan, Y.S.; Yang, C.H.; Han, Y.Z. Research on catalytic oxidation of dimethyl ether to dimethoxymethane over $\mathrm{MnCl}_{2}$ modified heteropolyacid catalysts. Catal. Commun. 2008, 9, 1916-1919. [CrossRef]

15. Zhang, Q.D.; Tan, Y.S.; Yang, C.H.; Liu, Y.Q.; Han, Y.Z. Catalytic oxidation of dimethyl ether to dimethoxymethane over $\mathrm{MnCl}_{2}-\mathrm{H}_{4} \mathrm{SiW}_{12} \mathrm{O}_{40} / \mathrm{SiO}_{2}$ catalyst. Chin. J. Catal. 2006, 27, 916-920. [CrossRef]

16. Leng, K.; Wang, Y.; Hou, C.; Lancelot, C.; Lamonier, C.; Rives, A.; Sun, Y. Enhancement of catalytic performance in the benzylation of benzene with benzyl alcohol over hierarchical mordenite. J. Catal. 2013, 306, 100-108. [CrossRef]

17. Zhang, J.; Wang, L.; Wang, G.; Chen, F.; Zhu, J.; Wang, C.; Bian, C.; Pan, S.; Xiao, F.-S. Hierarchical Sn-Beta Zeolite Catalyst for the Conversion of Sugars to Alkyl Lactates. ACS Sustain. Chem. Eng. 2017, 5, 3123-3131. [CrossRef]

18. Wei, X.; Smirniotis, P.G. Development and characterization of mesoporosity in ZSM-12 by desilication. Microporous Mesoporous Mater. 2006, 97, 97-106. [CrossRef]

19. Van Laak, A.N.; Gosselink, R.W.; Sagala, S.L.; Meeldijk, J.D.; De Jongh, P.E.; De Jong, K.P. Alkaline treatment on commercially available aluminum rich mordenite. Appl. Catal. A Gen. 2010, 382, 65-72. [CrossRef]

20. Keller, T.C.; Arras, J.; Wershofen, S.; Perez-Ramirez, J. Design of hierarchical zeolite catalysts for the manufacture of polyurethane intermediates. ACS Catal. 2015, 5, 734-743. [CrossRef]

21. Sazama, P.; Sobalík, Z.; Dědeček, J.; Jakubec, I.; Parvulescu, V.; Bastl, Z.; Rathousky, J.; Jirglová, H. Enhancement of Activity and Selectivity in Acid-Catalyzed Reactions by Dealuminated Hierarchical Zeolites. Angew. Chem. 2013, 125, 2092-2095. [CrossRef]

22. Pastvova, J.; Kaucky, D.; Moravkova, J.; Rathousky, J.; Sklenak, S.; Vorokhta, M.; Brabec, L.; Pilar, R.; Jakubec, I.; Tabor, E.; et al. Effect of Enhanced Accessibility of Acid Sites in Micromesoporous Mordenite Zeolites on Hydroisomerization of n-Hexane. ACS Catal. 2017, 7, 5781-5795. [CrossRef]

23. Zhang, J.; Rao, C.; Peng, H.; Peng, C.; Zhang, L.; Xu, X.; Liu, W.; Wang, Z.; Zhang, N.; Wang, X. Enhanced toluene combustion performance over Pt loaded hierarchical porous MOR zeolite. Chem. Eng. J. 2018, 334, 10-18. [CrossRef]

24. Zhao, H.Y.; Bennici, S.; Shen, J.Y.; Auroux, A. Nature of surface sites of catalysts and reactivity in selective oxidation of methanol to dimethoxymethane. J. Catal. 2010, 272, 176-189. [CrossRef]

25. Chen, S.; Wang, S.; Ma, X.; Gong, J. Selective oxidation of methanol to dimethoxymethane over bifunctional VOx/TS-1 catalysts. Chem. Commun. 2011, 47, 9345. [CrossRef] [PubMed]

26. Huang, X.M.; Li, Y.G.; Xu, Y.D.; Shen, W.J. Kinetics of selective oxidation of dimethyl ether to formaldehyde over $\mathrm{Al}_{2} \mathrm{O}_{3}$-supported $\mathrm{VO}_{\mathrm{x}}$ and $\mathrm{MoO}_{\mathrm{x}}$ catalysts. Catal. Lett. 2004, 97, 185-190. [CrossRef]

27. Cheung, P.; Liu, H.; Iglesia, E. Effects of $\mathrm{Al}_{2} \mathrm{O}_{3}$ support modifications on $\mathrm{MoO}_{\mathrm{x}}$ and $\mathrm{VO}_{\mathrm{x}}$ catalysts for dimethyl ether oxidation to formaldehyde. Phys. Chem. Chem. Phys. 2003, 5, 3795.

28. Zhang, W.; Meng, T.; Tang, J.; Zhuang, W.; Zhou, Y.; Wang, J. Direct Synthesis of 2, 5-Diformylfuran from Carbohydrates Using High-Silica MOR Zeolite-Supported Isolated Vanadium Species. ACS Sustain. Chem. Eng. 2017, 5, 10029-10037. [CrossRef]

29. Kowalska-Kus, J.; Held, A.; Frankowski, M.; Nowinska, K. Solketal formation from glycerol and acetone over hierarchical zeolites of different structure as catalysts. J. Mol. Catal. A Chem. 2017, 426, 205-212. [CrossRef]

30. Fu, W.H.; Liang, X.M.; He, M.Y.; Zhang, H.; Wang, Y.M. Shape selectivity extending to ordered supermicroporous aluminosilicates. Chem. Commun. 2015, 51, 1449-1452. [CrossRef]

31. Góra-Marek, K.; Tarach, K.A.; Tekla, J.; Olejniczak, Z.; Kuśtrowski, P.; Cheng, L.; Martínez-Triguero, J.; Rey, F.; Liu, L. Hierarchical Mordenite Dedicated to the Fluid Catalytic Cracking Process: Catalytic Performance Regarding Textural and Acidic Properties. J. Phys. Chem. C 2014, 118, 28043-28054. [CrossRef]

32. Harlin, M.; Niemi, V.; Krause, A. Alumina-Supported Vanadium Oxide in the Dehydrogenation of Butanes. J. Catal. 2000, 195, 67-78. [CrossRef] 
33. Meng, Y.L.; Wang, T.; Chen, S.; Zhao, Y.J.; Ma, X.B.; Gong, J.L. Selective oxidation of methanol to dimethoxymethane on $\mathrm{V}_{2} \mathrm{O}_{5}-\mathrm{MoO}_{3} /$ gamma- $\mathrm{Al}_{2} \mathrm{O}_{3}$ catalysts. Appl. Catal. B 2014, 160, 161-172. [CrossRef]

34. Lim, T.H.; Nam, K.; Song, I.K.; Lee, K.-Y.; Kim, D.H. Effect of Si/Al 2 ratios in Mo/H-MCM-22 on methane dehydroaromatization. Appl. Catal. A Gen. 2018, 552, 11-20. [CrossRef]

35. Steinfeldt, N.; Muller, D.; Berndt, $\mathrm{H}_{\text {. }} \mathrm{VO}_{\mathrm{x}}$ species on alumina at high vanadia loadings and calcination temperature and their role in the ODP reaction. Appl. Catal. A Gen. 2004, 272, 201-213. [CrossRef]

36. Arena, F.; Frusteri, F.; Martra, G.; Parmaliana, A.; Coluccia, S. Surface structures, reduction pattern and oxygen chemisorption of $\mathrm{V}_{2} \mathrm{O}_{5} / \mathrm{SiO}_{2}$ catalysts. J. Chem. Soc. Faraday Trans. 1997, 93, 3849-3854. [CrossRef]

37. Wang, W.; Gao, X.; Yang, Q.; Wang, X.; Song, F.; Zhang, Q.; Han, Y.; Tan, Y. Vanadium oxide modified H-beta zeolite for the synthesis of polyoxymethylene dimethyl ethers from dimethyl ether direct oxidation. Fuel 2019, 238, 289-297. [CrossRef]

38. Ma, M.; Zhan, E.; Huang, X.; Ta, N.; Xiong, Z.; Bai, L.; Shen, W. Carbonylation of dimethyl ether over Co-HMOR. Catal. Sci. Technol. 2018, 8, 2124-2130. [CrossRef]

39. Khandan, N.; Kazemeini, M.; Aghaziarati, M. Determining an optimum catalyst for liquid-phase dehydration of methanol to dimethyl ether. Appl. Catal. A Gen. 2008, 349, 6-12. [CrossRef]

(C) 2019 by the authors. Licensee MDPI, Basel, Switzerland. This article is an open access article distributed under the terms and conditions of the Creative Commons Attribution (CC BY) license (http://creativecommons.org/licenses/by/4.0/). 